\title{
CAMINHO CON(DI)VERGENTE PARA A EDUCAÇÃO DAS RELAÇÕES ÉTNICO- RACIAIS NAS LICENCIATURAS DO CAMPUS JK DA UFVJM
}

\author{
PATH WITH VERGENTE (DI) FOR EDUCATION OF ETHNIC-RACIAL RELATIONSHIPS IN THE LICENSES OF \\ THE CAMPUS JK UFVJM
}

Marcelo Siqueira Jesus ${ }^{1}$ Alan Silva Aguiar ${ }^{2}$

\begin{abstract}
Resumo: $O$ presente trabalho é fruto de pesquisa que objetivou conhecer a realidade da implementação de conteúdos sobre história e cultura de África e dos afro-brasileiros nos Projetos Pedagógicos de Curso das Licenciaturas presenciais do Campus JK da Universidade Federal dos Vales do Jequitinhonha e Mucuri (UFVJM), nos seguintes cursos: Ciências Biológicas, Educação Física, Geografia, História, Letras, Pedagogia e Química. Verificamos nas matrizes curriculares dos cursos sinalizados quais, dentre eles, possuem conteúdos e disciplinas que dialogam com temas relacionados à Educação para Relações Étnico-Raciais, sobretudo, que visam atender às deliberações da Resolução CNE/CP nº 02/2015. Sobremaneira, essa pesquisa social, de caráter qualitativo, do tipo documental, analisou e coletou dados nos Projetos Pedagógicos de Cursos (PPCs). Buscamos acessar os referidos documentos através do site da UFVJM e de páginas da web dos respectivos cursos analisados. Após a análise de dados, consideramos que os cursos de graduação presenciais das Licenciaturas do Campus JK da UFVJM atendem parcialmente às deliberações da Resolução $\mathrm{CNE} / \mathrm{CP} \mathrm{n}^{\circ}$ 02/2015, além das legislações antirracistas - Lei Federal $n^{\circ}$. 10.639/03 e Lei Federal $n^{\circ}$. 11.645/08. Consideramos que há um longo caminho para implementar efetivamente uma educação antirracista no currículo dos cursos de formação dos futuros profissionais da educação básica egressos desta instituição de ensino público superior, inserida na região do Vale do Jequitinhonha, estado de Minas Gerais.
\end{abstract}

Palavras-Chave: Educação; Política Pública. Ensino Superior. Educação para Relações Étnico-Raciais. Formação de Professores.

\begin{abstract}
The present work is the result of research that aimed to understand the reality of the implementation of content on the history and culture of Africa and Afro-Brazilians, in the Pedagogical Course Projects, in-person Licentiate degrees, at the JK Campus, at the Federal University of Vales do Jequitinhonha and Mucuri, in the following courses: Biological Sciences, Physical Education, Geography, History, Letters, Pedagogy and Chemistry. We verified in the curricular matrices of the signposted courses, among them, which have contents and disciplines that dialogue with themes related to Education for Ethnic-Racial Relations, above all, which aim to meet the resolutions of Resolution CNE / CP no. 02/2015? This social research, of a qualitative nature, of documentary type, analyzed and collected data in the Pedagogical Course Projects (PPCs). We seek to access these documents through the UFVJM website and web pages of the respective courses analyzed. After analyzing the data, we consider that the face-to-face undergraduate courses of the Licenciaturas, at Campus JK, at UFVJM, partially meet the resolutions of Resolution CNE / CP n ${ }^{\circ} 02 / 2015$, in addition to the anti-racist legislation: Federal Law $n^{\circ} .10 .639$ / 03 and Federal Law no. 11,645 / 08 . We believe that there is a long way to effectively implement anti-racist education in the curriculum of training courses for future professionals of basic education, graduates of this institution of higher public education, inserted in the region of Vale do Jequitinhonha, State of Minas Gerais.
\end{abstract}

Keywords: Education. Public policy; University education. Education for Ethnic-Racial Relations. Teacher training.

Resumen: El presente trabajo es el resultado de una investigación que tuvo como objetivo comprender la realidad de la implementación de contenidos sobre la historia y la cultura africana y afrobrasileña, en los Proyectos del Curso Pedagógico, Licenciaturas presenciales, en el Campus JK, en la Universidad Federal de Vales do Jequitinhonha y

\footnotetext{
${ }^{1}$ Doutor em Educação pela Universidade Federal Fluminense e professor do Departamento de Educação Física da Universidade Federal dos Vales do Jequitinhonha e Mucuri - Campus JK. E-mail: marcelosjesus1975@hotmail.com. Orcid: https://orcid.org/0000-0002-5140-9290.

2 Licenciado em Educação Física pela Universidade Federal dos Vales do Jequitinhonha e Mucuri. E-mail: lanzao.14@gmail.com. Orcid: https://orcid.org/0000-0003-3021-0570.
} 
Mucuri, en los siguientes cursos: Ciencias Biológicas, Educación Física, Geografía, Historia, Letras, Pedagogía y Química. Verificamos en las matrices curriculares de los cursos señalizados, entre ellos, que tienen contenidos y disciplinas que dialogan con temas relacionados con la Educación para las Relaciones Étnico-Raciales, sobre todo, que tienen como objetivo dar cumplimiento a las resoluciones de la Resolución CNE / CP no. 02/2015? Esta investigación social, de carácter cualitativo, de tipo documental, analizó y recogió datos en los Proyectos de Curso Pedagógico (PPC). Buscamos acceder a estos documentos a través del sitio web de la UFVJM y páginas web de los respectivos cursos analizados. Tras analizar los datos, consideramos que los cursos presenciales de las Licenciaturas, en el Campus JK, en la UFVJM, cumplen parcialmente con las resoluciones de la Resolución CNE / CP nº 02/2015, además de la normativa antirracista: Ley Federal $n^{\circ} .10 .639$ / 03 y la Ley Federal no. 11.645 / 08. Creemos que hay un largo camino para implementar eficazmente la educación antirracista en el plan de estudios de los cursos de formación para los futuros profesionales de la educación básica, egresados de esta institución de educación superior pública, insertada en la región de Vale do Jequitinhonha, Estado de Minas Gerais.

Palabras clave: Educación. Política pública. Enseñanza superior. Educación para las relaciones étnico-raciales. Formación de profesores.

\section{PRIMEIRAS APROXIMAÇÕES A UM TEMA RECENTEMENTE RECORRENTE}

As políticas públicas de ações afirmativas têm alcançado notoriedade na agenda pública brasileira, devido a real possibilidade de inclusão e mobilidade social ascendente de pretos e pardos brasileiros, e pela inserção de saberes que representam a diversidade étnico-racial brasileira nos diferentes espaços de formação escolarizada e acadêmica (BRASIL, 2013).

Este artigo apresenta resultado de investigação social do tipo documental que buscou conhecer a realidade da implementação dos conteúdos afro-brasileiros e/ou sobre história de África nos currículos de cursos de formação de professores para atuação na educação básica.

Desenvolvemos uma investigação que teve como objetivo realizar leitura e análise de dados coletados dos Projetos Pedagógicos de Curso (PPC), das Licenciaturas, na modalidade presencial, localizadas no Campus JK, da Universidade Federal dos Vales do Jequitinhonha e Mucuri (UFVJM). Interessou-nos conhecer sobre a inclusão de conteúdos afro-brasileiros e de história da África nas matrizes curriculares dos seguintes cursos de graduação: Ciências Biológicas, Educação Física (Licenciatura), Geografia, História, Letras, Pedagogia e Química.

Justificamos a realização da pesquisa em razão da falta de debates e conteúdos sobre as questões étnico-raciais na educação básica da rede pública estadual e municipal da microrregião de Diamantina, em Minas Gerais, e pelo silêncio no meio acadêmico da UFVJM quando se trata de Educação para Relações Étnico-Raciais.

Adotamos a Resolução CNE/CP n. 02/2015³ (BRASIL, 2015) como marco referencial para formulação do problema a ser investigado, em virtude de essa legislação ter definido Diretrizes Curriculares Nacionais para formação inicial em nível superior, dentre outros, dos cursos de Licenciatura, e conforme nos revela em seu capítulo $V$, art.13, define que:

Os cursos de formação deverão garantir nos currículos conteúdos específicos da respectiva área de conhecimento ou interdisciplinares, seus fundamentos e metodologias, bem como conteúdos relacionados aos fundamentos da educação, formação na área de políticas públicas e gestão da educação, seus fundamentos e metodologias, direitos humanos, diversidades étnico-racial, de gênero, sexual, religiosa, de faixa geracional, Língua Brasileira de Sinais (Libras), educação especial e direitos educacionais de adolescentes e jovens em cumprimento de medidas socioeducativas (BRASIL, 2015, p. 11).

Esta decisão legal associa-se às deliberações das Leis Federais n.10.639/03 (BRASIL, 2003) e

${ }^{3}$ A Resolução CNE/CS n ${ }^{\circ}$. 02/2019 insere alguns aditivos e substitui outros termos designados pela Resolução CNE/CP $n^{\circ}$. 02/2015, no entanto, essa pesquisa aconteceu anteriormente a promulgação deste documento legal, e ainda, estamos sob vigência da Resolução anterior, e os cursos de graduação terão prazo para adequação a essa nova medida legal. Salientamos a importância/relevância de desenvolver investigação e saber sobre as alterações que os cursos de graduação, preferencialmente, as Licenciaturas em inserir dados que visam adequar-se a Base Nacional Curricular Comum. 
$n^{\circ}$.11.645/08 (BRASIL, 2008), que tornam imprescindível que haja no currículo de formação do futuro profissional da área da educação básica, a presença de disciplinas ou unidades curriculares que contemplem conteúdos que problematizem o racismo 4 na sociedade brasileira.

Torna-se essencial no currículo escolar apresentar problematização das diferenças raciais e fenotípicas, que estão correlacionadas às condicionantes sociais de oportunidade e posição de privilégios. A população negra é maioria no total populacional em nosso país, mas essa maior parcela da população não tem garantias de cidadania plena, e está representada em elevados dados estatísticos de vulnerabilidade social, vítimas de homicídio, altas taxas de desemprego, amplo crescimento entre a população carcerária, baixa escolaridade e reduzidas oportunidades de mobilidade social ascendente (IBGE, 2010)

As universidades públicas são espaços de privilégios e, na realidade de alguns cursos de graduação, a população branca é majoritária. Carvalho (2006) corrobora nesta assertiva quando analisa o percentual de discentes negros e de docentes negros no ensino superior, e considera ser muito baixo se comparado ao de discentes e docentes brancos em cursos de maior status e expressão social. Por outro lado, os trabalhadores terceirizados dessas universidades são negros em sua maioria, que executam ações laborais braçais e manuais, tais como: auxiliares de serviços gerais, zeladores, seguranças, entre outras. Seria correto naturalizar que as ocupações intelectuais sejam sinônimo de trabalho para brancos e, em contrapartida, estariam as ocupações braçais e manuais designadas aos trabalhadores pretos e pardos?

É preciso desnaturalizar as práticas do racismo institucional através de uma ação pedagógica e curricular, que vise oportunizar a formação do futuro educador e busque adotar melhor compreensão sobre as questões étnico-raciais no Brasil. Tal exposição é representada pelo sentido de descolonização dos currículos, que Gomes (2012) esclarece:

Descolonizar os currículos é mais um desafio para a educação escolar. Muito já denunciamos sobre a rigidez das grades curriculares, o empobrecimento do caráter conteudista dos currículos, a necessidade de diálogo entre escola, currículo e realidade social, a necessidade de formar professores e professoras reflexivos e sobre as culturas negadas e silenciadas nos currículos (GOMES, 2012, p. 102).

Portanto, essa educação antirracista deve ser oportunizada desde a educação básica, nos diversos níveis e modalidades de ensino. Compreendemos que a Resolução CNE/CP nº. 02/2015 (BRASIL, 2015) buscou orientar os PPCs dos Cursos de Licenciatura, com intuito de preparar seus Licenciandos, através da ampliação e/ou implementação de disciplinas ou unidades curriculares que corroboram para promoção de uma Educação para Relações Étnico-Raciais.

A presença destes conteúdos da diáspora africana na didática e no currículo possibilita garantir equidade, devido à hegemônica representação do currículo eurocêntrico. No entanto, passada a primeira década da implementação das Leis Federais antirracistas ${ }^{6}$, ainda é ineficaz a presença de disciplinas, debates, projetos voltados à Educação das Relações Étnico-Raciais no Ensino Superior. Carvalho (2006) considera que nas universidades os mecanismos mais comumente ativos que dão continuidade à prática da segregação racial são: a postergação da discussão, o silêncio sobre os conflitos raciais, a censura discursiva quando o tema racial manifesta-se e o disfarce para evitar posicionamentos claros contra o

\footnotetext{
4 Entre os aspectos que devem ser destacados na leitura crítica da realidade social que analisa o racismo, destacamos: a segregação racial, a exclusão social; desigualdades educacionais e raciais; intolerância religiosa; minorias étnicas e tantas outras questões que são silenciadas na sociedade, inclusive no meio acadêmico.

5 IBGE - Instituto Brasileiro de Geografia e Estatística, Censo 2010. Disponível em: https://ww2.ibge.gov.br/english/estatistica/populacao/cens02010/caracteristicas_da_populacao/tabelas_pdf/tab 3.pdf Último acesso em: 23/10/2018.

${ }^{6}$ Lei Federal $n^{\circ} .10 .639 / 03$ e Lei Federal n.11.645/08.
} 
racismo.

A falta de debates sobre os conceitos raça e racismo entre os atores sociais envolvidos nas ações curriculares, dos processos educativos de formação acadêmica nos cursos de Licenciatura, torna-se, sem dúvida, um fator determinante que refletirá no despreparo do futuro profissional para lidar com as questões das desigualdades raciais, seja no meio escolar ou na comunidade da qual é egresso ou está inserido. E, para o Licenciando, os debates que inserem a diversidade étnico-racial em sua pauta contribuirão de forma contundente em sua formação. Gomes (2005) considera que:

O entendimento conceptual sobre o que é racismo, discriminação racial e preconceito, poderia ajudar os (as) educadores(as) a compreenderem a especificidade do racismo brasileiro e auxiliá-los a identificar o que é uma prática racista e quando esta acontece no interior da escola. Essa é uma discussão que deveria fazer parte do processo de formação dos professores (GOMES, 2005, p. 147).

Desse modo, nosso interesse em realizar investigação no tema políticas públicas de inclusão étnicoracial no ensino superior justifica-se em razão de consideramos de suma importância a ampliação e acompanhamento dessa medida legal, que, uma vez publicizada, corrobore para desenvolver o senso crítico e autônomo dos leitores. Na formação de opinião sobre o tema, que contribua para que os sujeitos acumulem conhecimentos que potencializem a argumentação e problematização sobre a monocultura promovida pela visão curricular eurocêntrica, amplamente influente em nossa sociedade. E, sobretudo, que possibilite intervir e buscar estratégias para superar a segregação racial no currículo escolar.

\section{REVISÃO DE LITERATURA}

Apresentamos a revisão de literatura nesta sessão, na qual revisamos a teoria adotada para o desenvolvimento da pesquisa. Destacamos autores que evidenciam as diferenças raciais presentes nos diferentes meios sociais e, ainda, revelam a importância da promoção de uma educação antirracista a fim de proporcionar um senso crítico por parte dos sujeitos ou atores sociais, que passam a ter a oportunidade de acesso aos diferentes saberes da correlacionados à diáspora africana e aos valores civilizatórios dos diversos povos indígenas do Brasil.

Em relação aos problemas raciais ainda recorrentes em nossa sociedade e diante da teoria selecionada, recorremos aos autores que trazem perspectivas contundentes, que emitem uma dialética do axé, que visa compreender os fenômenos sociais dos quais se baseiam os manifestos da cultura da diáspora africana no Brasil e propor ações pedagógicas que potencializam a superação da discriminação racial, a quebra de hegemonia do eurocentrismo no currículo escolar. Enumeradas às outras medidas, estas visam contribuir para a redução das amplas taxas de desigualdades educacionais e raciais, sobremaneira, através da inclusão da cultura de matriz africana e de matriz indígena nas ações pedagógicas, didáticas e curriculares, entre outros temas pertinentes ao campo das relações étnicoraciais.

Os problemas raciais são frequentes em todo o mundo (IANNI, 1996). No Brasil, o preconceito racial é um fato, presente no cotidiano social, em diferentes espaços sociais, seja em empresas, campos de futebol, boates, praças, centros de ensino, entre outros. Porém, há na população brasileira uma determina dificuldade de assumir que vivemos em um país racista, e ainda, destacam-se exemplos históricos de outros países, como na África do Sul e o seu o Apartheid, ou a discriminação racial nos Estados Unidos, para justificar que eles é que são racistas (MUNANGA, 2010). Entre nós, brasileiros, a questão das relações raciais caracteriza-se como:

[...] o maior problema da maioria entre nós parece estar em nosso presente, em nosso cotidiano de brasileiras e brasileiros, pois temos ainda bastante dificuldade para entender e decodificar as manifestações do nosso racismo à brasileira, por causa de suas peculiaridades que o diferenciam das outras formas de manifestações de racismo (MUNANGA, 2010, p. 170).

Kabengele Munanga (2010) considera que as diferenças são o alicerce para a presença de preconceitos, seja através de aspectos de gênero, classe social, idade, sexo, religião, raça, entre outros, que são considerados enquanto problemas sociais. E, devido ao mito da democracia racial, cria-se uma 
ISSN $1983-1579$

Doi: 10.22478/ufpb.1983-1579.2020v13nEspecial.54715

http://periodicos.ufpb.br/ojs2/index.php

dificuldade para se admitir que exista o racismo no Brasil, e que este é um problema que precisa ser resolvido.

Martha Abreu e Hebe Mattos (2008) buscam dialogar sobre as diferenças étnico-raciais dando ênfase no parecer aprovado pelas Diretrizes:

As Diretrizes trazem para o âmbito da escola, pela primeira vez, a importante discussão das relações raciais no Brasil e o combate ao racismo, tantas vezes silenciado ou desqualificado pelas avaliações de que o Brasil é uma democracia racial. [...] o parecer se propõe oferecer uma resposta, entre outras, na área da educação, à demanda da população afro-descendente, no sentido de políticas de ações afirmativas, isto é, de políticas de reparações, e de reconhecimento e valorização de sua história, cultura, identidade (ABREU; MATTOS, 2008, p. 9).

Em termos culturais, as Diretrizes Curriculares para o Ensino de História e Cultura Afro-brasileira (BRASIL, 2003) procuram reafirmar a inserção da cultura brasileira de matriz africana e História de África nos currículos escolares em todos os níveis e modalidades da educação brasileira. Constituem uma tentativa de superar a hegemonia do currículo com características do eurocentrismo, no qual, historicamente, apresentou-se uma desvalorização dos valores civilizatórios africanos.

Nesta pesquisa, consideramos o conceito de africanidades brasileiras para categorizar conteúdos escolares correlacionados aos valores civilizatórios da diáspora africana no Brasil. Para a utilização de tal conceito, recorremos a Petronilha Beatriz Gonçalves e Silva (2005), que apresenta argumentos sobre concepções e métodos que atendam à finalidade de implementar as africanidades no currículo escolar brasileiro:

[...] estudar as Africanidades Brasileiras significa tomar conhecimento, observar, analisar um jeito peculiar de ver a vida, o mundo, o trabalho, de conviver e de lutar pela dignidade própria, bem como pela de todos descendentes de africanos, mais ainda de todos que a sociedade marginaliza. Significa também conhecer e compreender os trabalhos e criatividade dos africanos e de seus descendentes no Brasil, e de situar tais produções na construção da nação brasileira (SILVA, 2005, p. 156).

Com essa implementação, o discente, seja da educação básica ou do ensino superior, passa a ter um entendimento mais amplo dos valores e tradições civilizatórios de matriz africana, das diversidades étnico-raciais, das origens africanas e da sua contribuição no processo da construção econômico, social e cultural do nosso país. Silva (2005) compreende que as africanidades brasileiras, ao estarem presentes tanto no meio escolar e/ou no meio acadêmico, podem ser organizadas no currículo, abrangendo diferentes disciplinas, e também inseridas no campo da pesquisa e da extensão, tendo como elementos centrais norteadores a cultura e a história dos diferentes povos de África, e dos povos que resultaram da diáspora africana.

A verificação da presença destes saberes da diáspora africana e da questão racial nos currículos presenciais dos cursos de Licenciatura investigados na pesquisa que desenvolvemos adotou como referência a pesquisa realizada por Oliveira e Pessanha (2015), na Universidade Federal Fluminense (UFF), na cidade de Niterói-RJ, que teve como objetivo averiguar a inclusão de conteúdos étnico-raciais nos cursos de Licenciatura.

Oliveira e Pessanha (2015) entendem que a inclusão étnico-racial no currículo dos cursos de Licenciatura tem grande importância na formação de profissionais da educação, uma vez que no Brasil ainda é evidente a presença de problemas raciais no ambiente escolar. Por uma educação antirracista entendemos ser aquela que visa desenvolver ações pedagógicas em ambientes de escolarização que combatam quaisquer formas de discriminação pautadas por condições fenotípicas correlatas e que promovam acesso e oportunidade de conhecimento sobre valores civilizatórios africanos e indígenas (OLIVEIRA; PESSANHA, 2015). É necessário, neste contexto, para que se consiga compreender sobre a diversidade humana, as autoras ainda sinalizam que:

A racialização do mundo, que, no Brasil, foi incorporada através da proposta de 
branqueamento da população, traz até os dias atuais danos psíquicos que interferem gravemente nas relações inter-raciais, particularmente no ambiente escolar, no qual as denominações pejorativas são com frequência dirigidas aos negros por parte de colegas nem sempre brancos, havendo também situações de descriminação vindas de outros componentes do ambiente escolar, além da proveniente de materiais didáticos que, apesar das políticas contemporâneas, ainda apresentam situações racistas (OLIVEIRA; PESSANHA, 2015, p. 67).

Entretanto, a experiência da Universidade Federal Fluminense (UFF) não é a mesma de outras Instituições Federais de Ensino Superior (IFES), em razão do chamado confinamento racial, que fica mais evidenciado entre os membros do corpo docente: neste espaço universitário e acadêmico, a população branca é majoritária, seja em cargos de gestão, coordenações de extensão e pesquisa, e nas próprias ações de ensino. Carvalho (2006) denunciou quadro desigual entre os docentes do ensino público superior:

Após o censo racial docente na UnB, passei então a solicitar a ajuda dos meus colegas negros para conhecer a porcentagem de docentes negros em outras universidades públicas. Mesmo admitindo uma margem de erro nas amostragens por eles reunidas (e na verdade colocamos um percentual de $20 \%$ acima do número encontrado), deparamonos com situações chocantes, como as da USP, Unicamp, UFRJ e UFRGS, instituições em que a proporção de professores negros não passa de $0,2 \%$; a da UFSCAR, de $0,5 \%$ e a da UFMG, de $0,7 \%$. Dito de outro modo, em nenhuma universidade considerada como referência nacional na pesquisa esse número parece não passar de 1\% (CARVALHO, 2006, p. 91).

Este quadro apresentado no meio da primeira década do século XXI pode ter sofrido ampla alteração a partir de programas como o Reuni e da política de cotas na pós-graduação e da reserva de vaga nos processos de seleção para vaga no setor público? Este debate sobre o quadro desigual entre docentes brancos e negros é silenciado ou denunciado nas instituições públicas de ensino superior? Caso esteja silenciado, há confirmação de um confinamento racial?

José Jorge de Carvalho (2006) faz uma discussão sobre esse confinamento racial nas instituições acadêmicas brasileiras, buscando dialogar sobre a segregação racial que permeia pelo interior do ensino superior desde a sua criação em nosso país. Um dos fatores dessa segregação racial nas universidades está ligado à resistência a inclusão racial nesse meio, onde se sustenta a ideologia do mérito, sem levar em consideração outros determinantes como o fator econômico, e a desigualdade de oportunidades. Carvalho (2006, p. 92) esclarece que:

[...] a segregação racial no meio universitário jamais foi imposta no Brasil legalmente, mas sua prática concreta tem sido a realidade do nosso mundo acadêmico, através de mecanismos que esse próprio mundo acadêmico tem feito muito pouco por analisar e nem tem mostrado interesse, até recentemente, em desativá-los.

A questão racial no meio acadêmico é naturalizada, e isso se torna um problema, devido à ampliação das desigualdades raciais no Brasil. Numa pesquisa realizada nas universidades públicas brasileiras, em estudo de caso das instituições UERJ, UNEB e UnB, Jesus (2015) procurou analisar documentos sobre os programas de ações afirmativas, através da reserva de vagas ou cotas no acesso aos cursos de graduação destas três universidades brasileiras. A pesquisa revelou que as duas instituições estaduais adotaram a reserva de vaga com critério sociorracial, enquanto a UnB adotou a reserva de vaga com critério racial.

Jesus (2015) também considera que a Lei Federal de cotas, Lei $n^{\circ}$. 12.711/12, promoveu uma subsunção do critério raça sob a condição de classe, seja pela medida em atender egressos de escola pública e/ou pela comprovação de renda, em vista de atender ao critério social de baixa renda ou pobreza. E este é o fator que retirou raça da posição central da política de ação afirmativa de acesso ao ensino superior, deslocando-a para terceiro plano, e se mantiveram como questão central as chamadas cotas sociorraciais, nas quais prevalecem as questões sociais de classe. Assim esclarece o autor:

Considero que o programa de reserva racial da UnB visa combater o racismo e afirmo que nele a questão é central. No caso do programa de reserva de vaga da Uerj e da UneB, 
não se pode afirmar que isso também aconteça. Por mais que negros sejam sujeitos para os quais se destina a concessão da reserva, a questão racial foi deslocada para segundo e terceiro planos. As ações afirmativas da Uerj, UneB e UnB polarizaram a disputa entre o critério racial e o social nos conselhos universitários de outras instituições (JESUS, 2015, p. 178).

Diante disso, é necessário acompanhar o processo de implementação das políticas públicas de inclusão étnico-racial nos cursos de Licenciatura, e saber se há confirmação de que acontece a subsunção da categoria raça pela de classe nos currículos destes cursos de ensino superior investigados. Compreendemos que se é real a hierarquização de saberes e categorias nos currículos dos cursos de Licenciatura, tal fato pode ser compreendido como violação a legislação antirracista.

Consideramos significativo para o combate ao racismo institucional que, nos cursos de formação de docentes para Educação Básica, os Licenciandos tenham acesso aos conteúdos afro-brasileiros, da cultura de matriz africana e História e Cultura de África. Assim, caso não tenham essa oportunidade, configura-se a hipótese da possibilidade de manutenção de poder e status quo das ações curriculares eurocêntricas que estão em situação privilegiada e de hegemonia. Tal fato consumado reverberará nas redes públicas de educação básica, quer seja na continuidade do silêncio sobre o problema racial no Brasil, já encontrado nos diferentes sistemas educacionais, e na ausência de oportunidade, em que os discentes teriam acesso aos conteúdos que promovam o respeito às diferenças étnico-raciais, sobremaneira, em virtude de o profissional da educação não ter tido acesso aos conteúdos que dialogam com a temática étnico-racial em sua formação inicial para docência na Educação Básica.

Visando dar oportunidade a todos os sujeitos em processos de escolarização, na perspectiva de promover uma descolonização dos currículos escolares, Nilma Lino Gomes (2012) sugere a inserção dos conteúdos afro-brasileiros para promover uma efetiva educação para relações raciais 7 . De acordo com a autora, a superação da perspectiva eurocêntrica de conhecimento e do mundo torna-se um desafio para escola, aos educadores e as educadoras, ao currículo e a formação docente.

A implantação do ensino da História da África e das culturas afro-brasileiras oportunizou a inserção do diálogo sobre as diversidades culturais na sala de aula, e quando promove essa democracia étnica, esse diálogo se tornará emancipatório no ambiente escolar, contribuindo satisfatoriamente para a superação da perspectiva eurocêntrica de currículo. Gomes (2012, p. 105) corrobora essa perspectiva, ao destacar que:

O ato de falar sobre algum assunto ou tema na escola não é uma via de mão única. Ele implica respostas do "outro", interpretações diferentes e confrontos de ideias. A introdução da Lei n ${ }^{\circ} 10.639 / 03$ - não como mais disciplinas e novos conteúdos, mas como uma mudança cultural e política no campo curricular e epistemológico - poderá romper com o silêncio e desvelar esse e outros rituais pedagógicos a favor da discriminação racial.

Para dialogar com a questão racial e as políticas públicas de combate às desigualdades no Brasil, recorremos ao autor Mário Theodoro (2008), através das suas análises sociais e econômicas sobre o papel do negro na sociedade e a omissão do Estado para com os problemas raciais existentes em nosso país. Segundo Theodoro (2008), as chamadas políticas públicas, mediante as quais o Estado democrático de direito deveria garantir a consolidação de direitos, desfazer iniquidades e fortalecer a coesão social, mesmo obstruindo ciclos viciosos de reprodução de desigualdades em algumas promulgações, parecem ainda ausentes no caso do problema racial.

Devido ao mito da democracia racial, o Estado tende a oscilar quando o assunto é a existência de uma desigualdade racial, gerando assim uma escassez de programas de combate à discriminação racial e de políticas públicas para relações étnico-raciais. Theodoro (2008) lembra que

\footnotetext{
7 Quando destacamos no texto as relações raciais, sobretudo, interessa-nos preferencialmente, a perspectiva que
} analisa as desigualdades entre brancos e negros em nosso país. 
De fato, o mito da democracia racial, de algum modo vem legitimar e mesmo resgatar a igualdade como valor. Mas, ao mesmo tempo, desproblematiza, mitiga, e termina por rejeitar o reconhecimento da desigualdade racial como problema nacional, assim como o debate sobre suas causas e seus desdobramentos. É assim que a defesa da democracia racial, como ideário estruturante de nossa sociedade, ganha força e relevo no discurso contrário à adoção de políticas públicas ditas específicas para a população negra (THEODORO, 2008, p.168).

Porém, devido à ação do Movimento Negro $^{8}$ e de estudiosos do campo das relações étnico-raciais, esse mito da democracia racial tende a ser reduzido e desmitificado, devido à tomada de enunciação de poder (D'ADESKY, 2011), que representa o processo de emancipação do sujeito negro, a superação ao racismo, a compreensão sobre os mecanismos de distribuição de poder na sociedade brasileira e, finalmente, a tomada de voz frente aos processos excludentes, racistas e de manutenção do status quo. Tais processos de exclusão são cristalizados pelo privilégio dado à população branca, através de oportunidades de acesso às melhores ocupações e bens sociais, enquanto, em contrapartida, buscam manter o lugar da população negra na subalternidade e na alienação.

Consideramos relevante a seleção dos teóricos apresentados nesta sessão, devido ao compromisso e o rigor científico pelo qual desenvolvem pesquisas no campo das Relações Étnico-Raciais. Realizamos a leitura dos dados coletados na pesquisa sob o criterioso olhar teórico, e esse contato com a literatura reunida facilitou o trabalho de percepção sobre o material analisado. Apresentamos, a seguir, os dados coletados no campo de investigação.

\section{APRESENTAÇÃO DOS RESULTADOS DE PESQUISA}

Nesta sessão, apresentamos resultados coletados na pesquisa. Realizamos a análise baseada no referencial selecionado na revisão teórica. Dividimos apresentação em subtítulos, onde indicamos subtítulos, de temas correspondentes à Educação para Relações Étnico-Raciais.

Analisamos ementa, referencial bibliográfico e o corpo textual e, posteriormente, identificamos quais $\operatorname{cursos}^{9}$ possuem conteúdos e disciplinas que dialoguem com temas relacionados com a Educação para Relações Étnico-Raciais. Dividimos a apresentação nos seguintes subtítulos ou subtemas: Confinamento Racial; Presença do Tema Raça e Racismo; Ausência da população negra; Cultura de Matriz Africana em foco; Educação para Relações Étnico-Raciais; Literatura de matriz africana.

\subsection{Confinamento Racial}

Apresentamos a análise da temática "Confinamento Racial" e a definição deste subtema, que se baseia numa questão de preconceito racial nas universidades brasileiras, em razão de este pouco ser considerado por gestores e outros atores sociais deste espaço como um problema social a ser emergencialmente discutido. Tratar de confinamento racial, na opinião de Carvalho (2006), é pensar que as universidades brasileiras continuam segregadas, uma vez que nos seus corredores ainda se percebem resistências aos processos de inclusão étnica e racial.

A distinção social do problema racial se dá pela desigual presença majoritária da população branca em cursos denominados carreiras imperiais, que Hustana Maria Vargas (2010) considera se tratar daqueles cursos surgidos no período imperial, que ainda hoje são considerados de maior expressão e

\footnotetext{
${ }^{8}$ Algumas das ações protagonistas do Movimento Negro brasileiro na busca de implementação da política de ações afirmativas: Marcha Zumbi dos Palmares, Brasília, em 1995; Delegação brasileira e a participação do governo na Conferência de Durban, na África do Sul, 2001; Defesa pelas cotas raciais nas universidades públicas federais e estaduais, em diferentes cidades e capitais 2000- 2012. Luta em defesa pela constitucionalidade das Cotas Raciais da UnB durante tramitação da ADPF186 no Supremo Tribunal Federal, 2008 -2012.

${ }^{9}$ Lembramos que o objetivo dessa análise foi verificar nas matrizes curriculares dos seguintes cursos presenciais de Licenciatura, no Campus JK, da Universidade Federal dos Vales do Jequitinhonha e Mucuri: Ciências Biológicas, Educação Física (Licenciatura), Geografia, História, Letras, Pedagogia e Química, se a medida deliberativa da Resolução CNE/CP nº. 02/2015 está em pleno processo de implementação, sobretudo, nosso interesse é pela questão da Educação para Relações Étnico-Raciais, na disponibilidade de inserção de conteúdos que relacionam aspectos da cultura e história de África e dos afro-brasileiros.
} 
prestígio social: Medicina, Engenharias e Direito. Por outro lado, os cursos de Licenciatura têm oportunizado a inserção da população negra no ensino superior, já que nestes cursos o acesso tem sido mais democrático.

Nos cursos de licenciatura da UFVJM selecionados na pesquisa - Ciências Biológicas, Educação Física (Licenciatura), Geografia, História, Letras, Pedagogia e Química - não foram encontrados em seus respectivos PPCs, na ementa, no referencial bibliográfico e no corpo textual nada que se refira ao subtema confinamento racial e desigualdades raciais nas universidades brasileiras. Diante dessa ausência de discussão sobre este tema tão pertinente, passamos ao questionamento quanto ao lugar do negro no meio acadêmico, especialmente onde ele está em minoria, como aponta a representação demográfica nos quadros de docentes e de servidores públicos nas instituições de ensino público superior.

O silêncio sobre o problema racial no meio acadêmico brasileiro denuncia a exclusão racial no corpo docente, e só reforça a ideia de que há uma resistência quanto à inclusão racial nesse meio. Carvalho (2006, p. 91) opina que a condição de exclusão racial na profissão docente, sobremaneira no ensino superior, deve ser interpretada pelo viés da problemática racial construída na historicidade de nossa sociedade. É papel da universidade adotar uma posição de combate ao racismo institucional, devido à perspectiva racialista que baseia essa prática de discriminação ter relações diretas com a racionalidade científica, que demarca o ethos e habitus do espaço acadêmico universitário.

\subsection{Presença do Tema Raça e Racismo}

Este subtítulo apresenta a análise da temática "Raça e Racismo". Consideramos nesta análise os textos legais que pautam as Políticas Públicas de inclusão Étnico-Racial no ensino superior, a Resolução CNE/CP n ${ }^{\circ}$ 02/2015, a Lei $n^{\circ} .10 .639 / 03$ e a Lei $n^{\circ}$. 11.645/08. Após análise dos PPCs dos cursos de licenciatura da UFVJM selecionados na pesquisa, foi constatado que nem todos dispõem de conteúdos que abordam diretamente os temas raça e racismo.

A escola como formadora de opinião e cidadania tem a missão de promover em seus discentes o sentido de respeito à diversidade racial e às diferenças fenotípicas correlatas. Ao tomar conhecimento sobre os mecanismos que produzem o racismo, os discentes têm a oportunidade de posicionar-se criticamente, e adotar posição de denúncia aos problemas sociais vividos pela população negra em nosso país. Tal assertiva revela ser necessária a inclusão de conteúdos que dialoguem sobre a proposição de uma educação antirracista. O racismo pode ser entendido, segundo Theodoro (2008, p. 171) como:

Um conjunto de crenças e preceitos que moldam a ideia de superioridade de determinados grupos sobre outros, a partir da identificação de distinções raciais. Ele justifica e corrobora não apenas a discriminação racial, como o preconceito, entendido aqui como a individualização do racismo, sua reprodução no dia a dia, por meio de visões ou predisposições negativas face aos indivíduos negros.

Oliveira e Pessanha (2015) entendem que há uma escassez de estudos na educação básica relacionados às questões raciais, e compreendem que é nesse espaço de escolarização que há uma urgência de ser realizada uma educação antirracista. Porém, ainda faltam profissionais preparados para dialogar sobre estas questões.

Entre as necessidades constatadas no ambiente da escola básica, está a de oferecer aos profissionais, em exercício e em formação, oportunidade de realizar estudos sobre valores e sua importância na educação, porque ninguém nasce com valores e, portanto, é preciso ensiná-los. Desse modo, o licenciando precisa ter clareza sobre os valores que devem ser incorporados em uma educação com conteúdo antirracista (OLIVEIRA E PESSANHA, 2015, p. 66).

Na presente pesquisa, após a análise de dados, foi constatado que os cursos de Ciências Biológicas, História, Letras, Pedagogia e Química abordam em seus PPCs, a temática "Raça e Racismo": há sinalização destes temas no corpo textual, na ementa e nas referências bibliográficas. No curso de Ciências Biológicas, por exemplo, encontramos a disciplina ou unidade curricular "Educação e Relações ÉtnicoRaciais", que na ementa e na bibliografia indica abordagem sobre questões raciais pertinentes ao 
currículo, que auxiliarão a formação do futuro docente:

Estudo e análise introdutória sobre Educação e Relações Étnico-Raciais na Sociedade brasileira, e a perspectiva de compreensão das desigualdades sociais, tendo o racismo como objeto de análise. Com ênfase no campo educacional e seus protagonistas: população negra em busca de constituição e mudanças. Debate político e ideológico sobre raça e etnia, e suas implicações a outras questões do cotidiano social: classe, gênero, sexualidade, juventude, religiosidade, escolaridade e currículo. Diagnóstico e avaliação das políticas públicas de recorte focal, que buscam superar as demandas educacionais relacionadas a diversidade étnico-racial: na educação básica (Leis Federais $n^{\circ}$. 10.639/03 e $n^{\circ} .11 .645 / 08$ ) e no ensino superior (Lei Federal $n^{\circ} .12 .711 / 12$ ) (UFVJM, 2018).

O curso de Letras traz em seu corpo textual menções sobre o racismo, e espera que, a partir do conteúdo proposto, o licenciando reúna conhecimento que lhe potencialize a desenvolver estratégias pedagógicas de combate ao racismo, e busque valorizar a cultura afro-brasileira e a diversidade racial:

Construir sua atividade docente a partir de uma postura refletida e crítica a respeito das relações Étnico-Raciais e sobre o papel do professor no combate ao racismo e na "valorização da história e cultura dos afro-brasileiros e dos africanos" (CNE, 2004b, p.02), bem como na formação de "cidadãos atuantes e conscientes no seio da sociedade multicultural e pluriétnica do Brasil, buscando relações étnico-sociais positivas" (UFVJM, 2018).

Nos cursos de Educação Física e Geografia não encontramos dados que indicam estes temas em seus PPCs. Merece destaque que os PPCs investigados estão atualizados para atender a Resolução CNE/CP n. 02/2015, exceto o do curso de Educação Física (Licenciatura), que utiliza o PPC de 2014.

A ausência dos temas Raça e Racismo em determinados cursos é um fator preocupante, pois são temas que precisam ser debatidos, e a sua ausência revela tratar-se de racismo institucionalizado. Theodoro (2008, p. 172) compreende que a questão racial e a sua problemática somente será efetiva se ampliar o sentido de igualdade de oportunidade, que reconheça e valorize a diversidade de nossa sociedade, em espaços como a escola. Assim, a legislação antirracista será efetiva no combate ao preconceito racial.

\subsection{Ausência da denominação população negra}

Reunimos aqui os resultados da análise de dados relativos à temática "Ausência da População Negra". Justificamos a escolha deste subtema por entender que as histórias, saberes e cultura que corroborem na formação dos valores civilizatórios africanos e afro-brasileiros, devem ser essenciais na promoção de uma educação antirracista, e na realidade regional do campo e lócus de investigação. A população negra e seus saberes devem estar relacionados nas unidades curriculares, tendo em vista que a população do Vale do Jequitinhonha é majoritariamente negra (BRASIL, Censo IBGE, 2010).

A população brasileira é formada em sua maioria por negros (BRASIL, Censo IBGE, 2010), fato que deve ser considerado nas proposições e planejamentos curriculares da educação básica e do ensino superior. A garantia de inclusão de conteúdos que dialogam com a temática étnico-racial se cristaliza no currículo através da promoção da política de ações afirmativas ${ }^{10}$, a partir da premissa de maior reconhecimento e valorização dos aspectos sociais que cerceiam a diversidade étnico-racial.

A promoção de uma educação antirracista requer a adoção de estratégias pedagógicas que não somente insiram conteúdos que valorizem a cultura e diversidade étnico-racial, mas que também sejam capazes de potencializar o reconhecimento/pertencimento identitário da população negra pela sua própria cor, fenótipo ou raça; de reconhecer e intervir sobre os mecanismos de exclusão social e racial; e de dialogar com outros indicadores sociais que corroboram para revelar as desigualdades raciais. Entre tais desigualdades, adotando-se a perspectiva interseccional entre raça, gênero e classe, percebe-se que os negros possuem menor renda per capta em relação aos brancos, conforme revela Soares (2008, p. 119)

\footnotetext{
${ }^{10}$ Além das Leis Federais n¹0.639/03 e n.11.645/08, nos referimos, sobretudo, às Diretrizes Curriculares para o Ensino de História de África e cultura de afro-brasileiros (BRASIL, 2013).
} 
ISSN 1983-1579

Doi: 10.22478/ufpb.1983-1579.2020v13nEspecial.54715

http://periodicos.ufpb.br/ojs2/index.php

sobre dados da década entre 1998 a 2008:

\begin{abstract}
É fato conhecido no panorama das desigualdades brasileiras que há uma desigualdade racial considerável no país. Pretos e pardos, doravante denominados negros, têm menos que a metade da renda domiciliar per capita de brancos. Trata-se de uma desigualdade particularmente detestável dado que, como tem sido destacado em inúmeros estudos, parte significativa dela não é atribuível a nenhuma medida de mérito ou esforço, sendo puramente resultado de discriminações passadas ou presentes.
\end{abstract}

Os cursos de Ciências Biológicas, Geografia, História e Pedagogia destacam a temática "População Negra" em seu ementário, sendo o tema abordado no corpo textual, ementa e/ou bibliografia. No curso de Geografia, o tema é tratado na disciplina "Geografias Feministas", que tem em sua bibliografia complementar a referência: ALVAREZ \& SANTOS. Tradições negras, políticas brancas: previdência social e populações afro-brasileiras (2006).

O curso de Pedagogia traz dados satisfatórios em seu ementário, que compreendem as relações raciais no Brasil, e também estão presentes, numa bibliografia significativa de conteúdos que dialogam com a diversidade étnico-racial, raça e classe, identidade, etnia e população negra. Dos autores e autoras encontrados no documento deste curso, dentre eles, mencionamos dois expoentes do campo das relações étnico-raciais: Kabengele Munanga e Nilma Lino Gomes. Consideramos significante a descrição dos conceitos que norteiam o trabalho pedagógico em Educação para Relações Étnico-Raciais neste curso, conforme revela o seu ementário:

Conceitos relevantes nos estudos e pesquisas sobre relações étnico-raciais, dentre eles: raça, etnia, racialização, identidade, diversidade, diferença. Processos de colonização e pós-colonização. Perspectivas históricas da população negra e indígena no Brasil. Marcadores socioeconômicos e relações étnico-raciais na atualidade. Manifestações culturais afro-brasileira e indígena e seus contextos culturais. Relações étnico-raciais nos espaços educativos. Racismo e antirracismo na educação brasileira (UFVJM, 2018).

Os demais cursos de licenciatura, Educação Física, Letras e Química, não dialogam sobre o termo População Negra no seu Projeto Pedagógico de Curso. A ausência de discussões sobre a População Negra nos cursos de licenciatura abre um hiato sobre estudos e intervenções na Educação para Relações Étnicoraciais na Educação Básica, das redes públicas e privadas da região dos egressos das licenciaturas da UFVJM. Sobremaneira, os egressos desses cursos investigados não terão acumulado conhecimentos relacionados aos valores civilizatórios africanos e afro-brasileiros, que lhe ajudariam a desenvolver um plano de trabalho pedagógico antirracista. Essa ausência de acumulação de conhecimentos relativos a uma pedagogia antirracista compromete a autonomia do docente para debater sobre temas étnicoraciais na sala de aula. Em situação oposta, um currículo rico em conteúdos sobre história de África e cultura afro-brasileira potencializa compreender as relações raciais em nosso país. Gomes (2005, p. 149) lembra que:

E é justamente o campo dos valores que apresenta uma maior complexidade, quando pensamos em estratégias de combate ao racismo e de valorização da população negra na escola brasileira. Tocar no campo dos valores, das identidades, mexe com questões delicadas e subjetivas e nos leva a refletir sobre diversos temas presentes no campo educacional. Um deles se refere à autonomia do professor.

\title{
3.4 Cultura de Matriz Africana em foco
}

Consideramos a temática "Cultura de Matriz Africana" como aquela de maior importância para desenvolver uma pedagogia antirracista, devido à oportunidade de conhecer valores civilizatórios africanos, aspectos da diáspora africana que contribuíram na formação da cultura brasileira, saber sobre o sagrado e correlacionar com as religiões comparadas, e compreender as desigualdades raciais no Brasil. Confrontamos os dados coletados nos PPCs dos cursos selecionados na pesquisa para indicar a presença dos modos civilizatórios africanos e/ou práticas culturais de matriz africana nos documentos investigados.

De acordo com o Parecer CNE/CP 2/2004, ficaram instituídas as Diretrizes curriculares nacionais para 
a educação das relações étnico-raciais e para o ensino de história e cultura afro-brasileira e africana, visando a atender à Lei $n^{\circ}$ 10.639/2003, que estabeleceu a obrigatoriedade do ensino de história e cultura afrobrasileira e africana nas escolas do país. É um grande avanço, considerando o eurocentrismo existente na educação básica, na busca pela consolidação da pluralidade cultural e a diversidade étnico-racial. Abreu e Matos (2008, p. 6) afirmam que "é na verdade um dos sinais mais significativos de um novo lugar político e social conquistado pelos chamados movimentos negros e antirracistas no processo político brasileiro, e no campo educacional em especial".

Estas Diretrizes Curriculares buscam dar oportunidade para realização de uma igualdade cultural, através da valorização da presença da cultura de matrizes africana e indígena. E para esse reconhecimento de igualdade racial é necessário superar o aspecto monocultural eurocêntrico do currículo escolar. Abreu e Matos (2008, p. 12) sinalizam que:

\begin{abstract}
A história da cultura afro-brasileira e africana, entretanto, assim como a problematização desses conceitos, não tem recebido a mesma atenção e divulgação. Como todos os conceitos, eles precisam ser entendidos como categorias politicamente construídas ao longo da história por sujeitos e movimentos sociais que os trouxeram à tona (ou os recriaram) e os elegeram como fundamentais.
\end{abstract}

Compreendemos que, diante do compromisso ético e moral de combater o racismo institucional, é necessário que haja na matriz curricular de formação dos docentes para educação básica conteúdos que abordem o tema de História e Cultura de Matriz Africana, dando ênfase ao ensino e à valorização da cultura afro-brasileira e africana. Com isso, o egresso terá acumulado conhecimentos, dominará os códigos conceituais da relação entre raça, identidade negra, cultura negra, cultura afro-brasileira, pluralidade cultural e outros, correspondentes aos valores civilizatórios africanos.

Entre os cursos de licenciatura investigados, Ciências Biológicas, História, Letras, Pedagogia e Química, há em seus respectivos PPCs menção à temática da Cultura de Matriz Africana no corpo textual, ementa e bibliografia. O PPC do curso de História indica conteúdos que dialogam sobre a cultura africana, em particular, citamos o caso das disciplinas/unidades curriculares "História da África" e "Tópicos Especiais em História do Brasil”, além de informar na introdução do documento sobre a proposição pedagógica da Educação para Relações Étnico-Raciais e para o Ensino de História e Cultura Afro-brasileira e Africana:

O tema das relações étnico-raciais é enfatizado nas UC's obrigatórias: História da África e História Indígena nas Américas, podendo ser aprofundado nas UC's eletivas: Cultura e Identidade no Mundo Pós-Colonial; Tópicos especiais em História do Brasil e Tópicos em História da África. Como tema transversal está inserida nas unidades curriculares: História da América Portuguesa e História do Brasil Monárquico (UFVJM, 2018).

O curso de Química conta com a disciplina/unidade curricular "Educação, Cidadania e Direitos Humanos", pela qual sinaliza questões relacionadas à História e Cultura Afro-Brasileira e, consequentemente, à cultura de matriz africana. Esta disciplina mostra em sua ementa os seguintes dizeres:

Os Direitos Humanos e os sujeitos de direito. Raça, classe, gênero e etnia: as lutas dos movimentos sociais para a efetiva garantia dos Direitos Humanos. Multiculturalismo. Educação para a cidadania: diferentes abordagens pedagógicas e práticas escolares. Educação das Relações Étnico-Raciais e o Ensino de História e Cultura Afro-Brasileira e Africana (UFVJM, 2018).

Tecemos uma ponderação sobre o PPC do curso de Química, sobremaneira, ao subtema "Cultura de matriz africana em foco", em razão de considerar que a questão racial está subsumida na perspectiva dos Direitos Humanos, e também acontece subsunção a outras categorias, tais como: classe e gênero. Compreendemos que a presença de conteúdos brasileiros de matriz africana no currículo universitário alcança a denotação de promover justiça social, no entanto, percebemos no caso do PPC da Licenciatura em Química que a questão racial está sob a hierarquização do saber.

O curso de Educação Física sinaliza em seu PPC (2014) a temática da Cultura de Matriz Africana através da disciplina/unidade curricular "Capoeira e Cultura Popular", na qual relaciona a capoeira ao 
ISSN $1983-1579$

Doi: 10.22478/ufpb.1983-1579.2020v13nEspecial.54715

http://periodicos.ufpb.br/ojs2/index.php

ensino inicial da cultura afro-brasileira nas unidades escolares, conforme indicado em sua ementa:

Introdução à trajetória histórica da capoeira. Introdução aos movimentos básicos da capoeira: ginga, esquivas, golpes e movimentações. Introdução rítmica e musical da capoeira. Fundamentos da roda de capoeira. Introdução ao maculelê, puxada de rede e samba de roda. Reflexão da aplicação dos conteúdos na docência em educação física e suas relações com o ensino da cultura afro-brasileira nas escolas (UFVJM, 2014).

Não encontramos menção sobre o tema cultura de matriz africana no PPC do curso de Geografia (2018). A ausência de debates sobre a Cultura de Matriz Africana é, de fato, um problema no campo educacional, e essa carência de conteúdos na formação do profissional de educação básica corrobora ainda mais para o silêncio sobre as questões raciais no currículo escolar pelo Brasil. Esse quadro de ausência de debates da Cultura de Matriz Africana em espaços de escolaridade em nada acrescenta na luta pela erradicação de atos discriminatórios. Abreu e Matos (2008, p. 10) lembram que:

É importante tomar conhecimento da complexidade que envolve o processo de construção da identidade negra em nosso país. Processo esse marcado por uma sociedade que, para discriminar os negros, utiliza-se tanto da desvalorização da cultura de matriz africana como dos aspectos físicos herdados pelos descendentes de africanos.

\subsection{Educação para Relações Étnico-Raciais}

Tivermos interesse em conhecer a sensibilidade e o compromisso dos cursos de Licenciatura investigados, para implementar a Educação para Relações Étnico-Raciais e, de acordo com o que já foi mencionado sobre procedimento metodológico adotado nesta pesquisa, as fontes dos dados coletados são os Projetos Pedagógicos dos Cursos (PPC).

O campo da Educação para Relações Étnico-Raciais abrange muitos temas que têm certa urgência de serem debatidos nos diferentes centros educacionais do Brasil. Relacionamos alguns destes temas: racismo, diversidade étnico-racial, desigualdade racial, segregação racial, igualdade de oportunidades, entre outros. Na educação básica há um grande desafio em dialogar sobre as Relações Étnico-Raciais, devido ao pouco conhecimento acumulado pelos profissionais da educação em relação a este conteúdo. Gomes (2005) corrobora nessa afirmativa ao considerar que

O entendimento conceptual sobre o que é racismo, discriminação racial e preconceito, poderia ajudar os(as) educadores(as) a compreenderem a especificidade do racismo brasileiro e auxiliá-los a identificar o que é uma prática racista e quando esta acontece no interior da escola. Essa é uma discussão que deveria fazer parte do processo de formação dos professores (GOMES, 2005, p. 148).

Ainda recorremos a Gomes (2005, p. 146), quando afirma que "não há como negar que a educação é um processo amplo e complexo de construção de saberes culturais e sociais que fazem parte do acontecer humano". Sendo assim, é necessário que os educadores reconheçam que a escola é um espaço para se adquirir saberes além dos tradicionais, além do modelo eurocêntrico de ensino, e entender que no processo educacional deve-se trabalhar com certas dimensões, como diversidade, ética, sexualidade, culturas variadas, relações raciais, relações de gênero, entre outras.

Na presente análise dos dados investigados, todos os cursos de Licenciatura selecionados na pesquisa, Ciências Biológicas, Geografia, História, Letras, Pedagogia e Química citam a Educação para Relações Étnico-Raciais em seus respectivos PPCs, exceto o de Educação Física (2014).

Entretanto, no documento do curso de Educação Física, as Relações Étnico-Raciais são citadas na ementa da disciplina "Psicologia da Educação", porém, não encontramos bibliografia relacionada a este tema. Já no curso de Geografia, há em seu corpo textual menções sobre as relações étnico-raciais, como podemos conferir:

[...] formação que contemplasse o mínimo de $1 / 5$ em unidades curriculares com temáticas específicas do campo da educação, a saber: políticas públicas, psicologia da educação, direitos humanos, diversidade étnico-racial, gênero e sexual, educação 
especial, gestão da educação, dentre outros[...] (UFVJM, 2018).

O PPC do curso de Geografia sinaliza que algumas disciplinas adotam abordagem sobre as relações étnico-raciais: "Direitos Humanos e Diversidade", "Espaço e Poder", "Prática de Ensino em Educação e Sociedade" e, por fim, "Fundamentos e Práticas de Ensino em Geografia”. E o currículo do curso tende a deixar o futuro profissional, dentre outros quesitos, apto a:

Identificar questões e problemas socioculturais e educacionais, com postura investigativa, integrativa e propositiva em face de realidades complexas, a fim de contribuir para a superação de exclusões sociais, étnico-raciais, econômicas, culturais, religiosas, políticas, de gênero, sexuais e outras (UFVJM, 2018).

A falta de debate sobre as relações étnico-raciais fomenta a ideia de não existir uma equidade, e isso reforça o pensamento naturalizado de que as relações raciais não são questões para serem discutidas na educação. Ao nosso entendimento, isso é um equívoco. Os debates sobre questões raciais no meio educacional são de suma importância no processo educativo, e Gomes (2005) compreende que:

Ao entrar nesse debate, estamos questionando a nossa atuação profissional e a nossa postura ética diante da diversidade étnico-cultural e das suas diferentes manifestações no interior da escola. Que tipo de profissionais temos sido? A educação carece de princípios éticos que orientem a prática pedagógica e a sua relação com a questão racial na escola e na sala de aula (GOMES, 2005. p. 149).

\subsection{Literatura Negra}

Neste subtítulo destacamos apresentação de dados que revelam a presença de autores negros e da literatura negra nos PPCs das licenciaturas investigadas, quer seja representada por temas que problematizam a questão racial, ou na disponibilidade de inserção de poetas e literários egressos do continente africano e dos países da diáspora africana.

Justificamos a legitimidade de saber sobre a inserção da literatura africana e afro-brasileira nos documentos investigados em virtude da potencialidade que essa inserção contribui para desconstruir uma identidade eurocêntrica nas bibliografias. É de grande valia o reconhecimento e a valorização de obras escritas por autores negros, conforme Pessanha (2010) sinaliza:

Ao falarmos, portanto, de literatura negra, estamos nos referindo à presença de um "eu enunciador do discurso" que se quer e se afirma como negro, que expressa a consciência de um "existir negro", que reconhece o passado histórico do ancestral africano, que apresenta um olhar vivencial do modo de ver e sentir o mundo, de acordo com os valores da cultura negra (PESSANHA, 2010, p. 306).

Essa representatividade negra na literatura tem grande importância, por se tratar de um ato de desconstrução de algo que está enraizado na cultura brasileira e, consequentemente, conseguir elevar um novo pensamento coletivo, em que a história do negro passa a ser contada de acordo com quem a vive. É dar voz ao sujeito negro. Em um país cuja maioria da população é formada por negros, é de importância incalculável a presença negra nos diversos espaços da sociedade, inclusive no meio literário (PESSANHA, 2010).

Nos cursos de licenciatura selecionados na pesquisa, foram encontrados nos cursos de Ciências Biológicas, Letras, Pedagogia e Química, em seus respectivos PPCs (2018), a presença de autores negros. Podemos destacar o autor Kabengele Munanga, as autoras Iolanda de Oliveira e Nilma Lino Gomes, que trazem conteúdos bibliográficos ricos na tematização das relações étnico-raciais. É o caso do texto Teoria Social e Relações Sociais no Brasil Contemporâneo, escrito por Kabengele Munanga (2013), que traz questões pertinentes sobre o estudo de raça e classe, preconceito racial, entre outros temas direcionados à Educação para Relações Étnico-Raciais.

Nos cursos de Educação Física, Geografia e História não foram encontrados em seus respectivos PPCs, seja na ementa, no referencial bibliográfico e no corpo textual, nenhuma menção a autores negros ou literatura negra. Esse silêncio tende a implicar na busca pela legitimidade dessa literatura negra. Conforme Pessanha (2010, p. 307) esclarece: 
Como as obras literárias passam pelas instâncias legitimadoras que atuam condicionando sua consagração ou não e como estas instâncias estavam, no início, ligadas ao poder do branco europeu e à sua visão de mundo, podemos perceber por que muitas obras, principalmente da literatura negra, não foram contempladas no seio da literatura canônica.

Compreendemos que a literatura negra tem um papel importante na luta pela valorização e respeito à diversidade étnico-racial. Ter acesso às produções de autores negros potencializa aos infantis e juvenis em idade escolar a oportunidade de (re)conhecer diferentes expressões da cultura afrobrasileira. Entendemos que a adesão da literatura da diáspora torna-se um contraponto à perspectiva eurocêntrica, que é hegemônica no meio literário e acadêmico brasileiro.

\section{CONSIDERAÇÕES FINAIS}

A realização desta pesquisa oportunizou conhecer parte da materialidade da implementação da Resolução CNE/CP nº 02/2015 nos cursos presenciais de Licenciatura, do Campus JK da UFVJM. Nessa investigação, consideramos que o objetivo geral da pesquisa foi alcançado, porque efetivamente o trabalho conseguiu identificar alguns conteúdos que dialogam com as questões étnico-raciais. No entanto, em alguns documentos, é notória a presença parcial de diálogos sobre as desigualdades raciais e a promoção de uma pedagogia antirracista.

A presente pesquisa partiu da hipótese de que no meio educacional, tanto na Educação Básica quanto no Ensino Superior, a discussão sobre temas relacionados à Educação para Relações ÉtnicoRaciais está aquém das suas potencialidades e possibilidades. Esse problema persiste devido às resistências das instituições de ensino em promover inclusão étnico-racial.

Percebemos em nossa pesquisa que os cursos de graduação em Licenciatura no campus JK da UFVJM atendem parcialmente às deliberações da Resolução CNE/CP nº 02/2015, da Lei $n^{\circ}$. 10.639/03 e Lei $n^{\circ}$. 11.645/08. Assim, não contemplam integralmente o processo de inclusão étnico-racial em seus currículos. Compreendemos que a perspectiva de promoção de uma educação antirracista não é plena em todos os documentos analisados. Letras, Pedagogia, História e Ciências Biológicas são aqueles que mais se aproximam da perspectiva de pedagogia antirracista, enquanto Educação Física e Química apresentam parcialmente uma ação pedagógica antirracista, baseada na perspectiva da Educação para Relações Étnico-Raciais.

Consideramos que seja mister a continuidade de realização de investigações sobre a questão étnico-racial nestes cursos, com a promoção e ampliação de pesquisas que façam interface entre os projetos de ensino, pesquisa e de extensão. O tema das Relações Étnico-Raciais no Vale do Jequitinhonha é de ampla relevância, devido à historicidade da região e aos elevados dados que revelam manutenção e ampliação das desigualdades sociais, educacionais, raciais, entre outras que compõem o seu cenário social.

\section{REFERÊNCIAS}

ABREU, M; MATTOS, H. Em torno das "Diretrizes curriculares nacionais para a educação das relações étnico-raciais e para o ensino de história e cultura afro-brasileira e africana": uma conversa com historiadores. Estudos Históricos, Rio de Janeiro, v. 21, n. 41, p. 5-20, janeiro/junho de 2008.

BRASIL. Conselho Nacional de Educação. Define as Diretrizes Curriculares Nacionais para a formação inicial em nível superior (cursos de licenciatura, cursos de formação pedagógica para graduados e cursos de segunda licenciatura) e para a formação continuada. Resolução CNE/CP $n^{\circ}$. 02/2015, de $1^{\circ}$ de julho de 2015. Brasília. Diário Oficial da República Federativa do Brasil, Brasília-DF, seção 1, n. 124, p. 8-12, 02 de julho de 2015.

BRASIL. Lei $n^{\circ} 10.639$, de 9 de janeiro de 2003. Altera a Lei $n^{\circ} 9.394$, de 20 de dezembro de 1996, que estabelece as diretrizes e bases da educação nacional, para incluir no currículo oficial da Rede de Ensino a obrigatoriedade da temática "História e Cultura Afro-Brasileira", e dá outras providências. Diário Oficial, Brasília-DF, de 9 de janeiro de 2003. 
BRASIL. Lei n 11.645, de 10 março de 2008. Altera a Lei $n^{\circ} 9.394$, de 20 de dezembro de 1996, modificada pela Lei $n^{\circ} 10.639$, de 9 de janeiro de 2003, que estabelece as diretrizes e bases da educação nacional, para incluir no currículo oficial da rede de ensino a obrigatoriedade da temática "História e Cultura AfroBrasileira e Indígena". Diário Oficial, Brasília-DF, de 10 de março de 2008.

CARVALHO, J. J. O confinamento racial do mundo acadêmico brasileiro. Revista USP, São Paulo, n.68, p. 88-103, dezembro/fevereiro 2005-2006.

D’ADESKY, J. Do Direito à palavra ao Poder de Enunciação do Movimento Negro no Brasil. Revista NGUZU: Revista do Núcleo de Estudos Afro-Asiáticos (NEAA), da Universidade Estadual de Londrina (UEL), ano 1, n.1, março/julho de 2011, p.94-104. Disponível em: http://www.uel./files/miolo_revistanguzu.br. Acesso em: 18/10/2018.

GIL, A. C. Métodos e técnicas de pesquisa social. 1. ed. São Paulo: Atlas, 1997.

GOMES, N. L. Educação e Relações Raciais: Refletindo Sobre Algumas Estratégias de Atuação. In: MUNANGA, K. et al.(Orgs.). Superando o Racismo na Escola. 2.d. Brasília-DF: Ministério da Educação; Secretaria de Educação Continuada, Alfabetização e Diversidade (SECAD), 2005, p. 143-154.

GOMES, N. L. Relações étnico-raciais, educação e descolonização dos currículos. Currículo sem Fronteiras, v.12, n.1, pp. 98-109, Jan/Abr 2012.

GOMES, N. L. Relações Étnico-Raciais, Educação e Descolonização Dos Currículos. Currículo sem Fronteiras, Belo Horizonte, v.12, n.1, p. 98-109, janeiro/abril 2012.

IANNI, O. A racialização do mundo. Tempo Social Revista de Sociologia, v. 8, n. 1. São Paulo: USP, p. 1-23, 1996.

Disponível

em

http://www.fflch.usp.br/sociologia/temposocial/site/images/stories/edicoes/v081/a_racializacao.pdf

Acesso em: 05/03/2019.

JACCOUD, L. O combate ao racismo e à desigualdade: o desafio das Políticas Públicas de promoção da igualdade racial. In: As políticas públicas e a desigualdade racial no Brasil - 120 anos após a abolição. 1. ed. Brasília-DF: IPEA, 2008.

JESUS, M. S. Raça e classe nos projetos de cotas e/ou reserva de vagas nas universidades brasileiras. In: OLIVEIRA. I. Negritude e universidade: evidenciando questões relacionadas ao ingresso e aos projetos curriculares. Niterói-RJ: Alternativa, 2015.

MUNANGA, K. Teoria social e relações raciais no Brasil contemporâneo. In: OLIVEIRA, I. Cadernos PENESB: Especial Curso ERER. Niterói-RJ: Alternativa, n.12, p.169-203, 2010.

OLIVEIRA, I. PESSANHA, M. M. J. A questão racial nos currículos dos cursos de licenciatura e pedagogia ministrados pela Universidade Federal Fluminense. In: OLIVEIRA. I. Negritude e universidade: evidenciando questões relacionadas ao ingresso e aos projetos curriculares. Niterói-RJ: Alternativa, 2015.

PESSANHA, M. M. J. O negro na literatura. Cadernos PENESB. Niterói-RJ: Alternativa, n. 12, p. 1-390, 2010.

SÁ-SILVA, J. R.; ALMEIDA, C. D.; GUINDANI, J. F. Pesquisa documental: pistas teóricas e metodológicas. Revista Brasileira de História \& Ciências Sociais. [S.I.]: 2. ed. Julho de 2009.

SILVA, B. G. P. Aprendizagem e Ensino Das Africanidades Brasileiras. In: MUNANGA, K. et al.(Orgs.). Superando o Racismo na Escola. 2.ed. Brasília-DF: Ministério da Educação; Secretaria de Educação Continuada, Alfabetização e Diversidade (SECAD), 2005. p. 155-172.

SOARES, S. A trajetória da desigualdade: a evolução da renda relativa dos negros no Brasil. In: As políticas públicas e a desigualdade racial no Brasil - 120 anos após a abolição. 1. ed. Brasília-DF: IPEA, 2008.

SOUZA, Celina. Políticas Públicas: uma revisão da literatura. Revista Sociologias, Porto Alegre: UFRGS, ano 8, n. 16., p.20-45, 2006.

THEODORO, M. A guisa de conclusão: O difícil debate da questão racial e das políticas públicas de combate a desigualdade e a discriminação racial no Brasil. In: As políticas públicas e a desigualdade racial no Brasil - 120 anos após a abolição. Brasília-DF: IPEA, 2008. 
UFVJM. Ministério da Educação. Projeto pedagógico do curso de graduação em Ciências Biológicas. Universidade Federal dos Vales do Jequitinhonha e Mucuri. Setembro, 2018. Disponível em: http://www.ufvjm.edu.br Acesso em: 10/04/2019.

UFVJM. Ministério da Educação. Projeto pedagógico do curso de Licenciatura em Educação Física. Universidade Federal dos Vales do Jequitinhonha e Mucuri. Fevereiro, 2014. Disponível em: http://www.ufvjm.edu.br Acesso em: 10/04/2019.

UFVJM. Ministério da Educação. Projeto pedagógico do curso de graduação em Geografia. Universidade Federal dos Vales do Jequitinhonha e Mucuri. Setembro, 2018. Disponível em: http://www.ufvjm.edu.br Acesso em: 10/04/2019.

UFVJM. Ministério da Educação. Projeto pedagógico do curso de graduação em História. Universidade Federal dos Vales do Jequitinhonha e Mucuri. Setembro, 2018. Disponível em: http://www.ufvjm.edu.br Acesso em: 10/04/2019.

UFVJM. Ministério da Educação. Projeto pedagógico do curso de graduação em Letras. Universidade Federal dos Vales do Jequitinhonha e Mucuri. Setembro, 2018. Disponível em: http://www.ufvjm.edu.br Acesso em: 10/04/2019.

UFVJM. Ministério da Educação. Projeto pedagógico do curso de graduação em Pedagogia. Universidade Federal dos Vales do Jequitinhonha e Mucuri. Setembro, 2018. Disponível em: http://www.ufvjm.edu.br. Acesso em: 10/04/2019.

UFVJM. Ministério da Educação. Projeto pedagógico do curso de graduação em Química. Universidade Federal dos Vales do Jequitinhonha e Mucuri. Julho, 2018. Disponível em: http://www.ufvjm.edu.br. Acesso em: 10/04/2019.

VARGAS, H. M. Sem perder a majestade: Profissões imperiais no Brasil. Revista Estudos de Sociologia, Araraquara-SP, V.15, n.28, p.107-124, 2010. Disponível em: http://www.seer.fclar.unesp.br/estudos/article/view/2553/2173 Acesso em: 20/05/2019.

Sites visitados:

Censo IBGE 2010, disponível em: https://ww2.ibge.gov.br/english/estatistica/populacao/cens02010/caracteristicas_da_populacao/tabelas _pdf/tab3.pdf Último acesso em: 23/10/2018.

Lei Federal n’.10639/03 e Lei Federal n.11645/08 Resolução CNE/CP nº2/2015 Disponível em: http://www.portal.mec.gov.br Acesso em: 20/10/2018.

Resolução CNE/CES nº2/2019. Disponível em: http://portal.mec.gov.br/publicacoes-paraprofessores/3000-uncategorised/62611-resolucoes-cne-ces-2018. Acesso em: 15/06/2019.

Recebido em: 23/08/2020

Alterações recebidas em: 28/09/2020

Aceito em: 29/09/2020

Publicado em: 11/12/2020 